\title{
Ventral Onlay Buccal Mucosa Graft in Complex Hypospadias Repair
}

\begin{abstract}
Introduction: Urethral reconstruction in complex hypospadias (severe primary or crippled) poses a significant challenge. We report our experience with ventral onlay buccal mucosa graft in complex hypospadias repair.

Materials and methods: 32 patients with complex hypospadias (16 severe primary and 16 crippled) underwent ventral onlay buccal mucosa graft urethroplasty with local tissue flap (tunica vaginalis or subcutaneous dartos flap) as a second layer coverage of the new urethra. Tunica vaginalis flap used in 18 cases and subcutaneous dartos flap used in 14 cases. BMG harvested in all cases from inner check by the technique described by Eppley et al.. ${ }^{1}$. Follow up ranged from 6 to 30 months. Early and late Complications reported. Success defined as patient has a straight penis with meatus at the tip of the glans without functional complications need reoperation procedures.
\end{abstract}

Results: 29 early complications (edema, bleeding \& hematoma, infection, catheter problems, glans dehiscence, wound dehiscence, fistula and graft loss) occurred in 10 patients $(31,25 \%) .13$ Late complications (meatal stenosis, urethral stricture, graft contracture and residual chordee) in 7 patients $(21,875 \%)$. Conservative management succeeds to decrease the number of patients those need reoperation procedures to $9 / 32(28.125 \%)$, for fistula closure, meatoplasty, orthoplasty and VIU. No donor site complications reported.

Conclusion: Buccal mucosa appears to be a durable source of non-genital tissue for urethral replacement. Onlay buccal mucosa urethroplasty for complex hypospadias repair is of good results obtained with both in one stage or two stage repair with better results in two stages approach.
Volume 5 Issue 3 - 2017

\author{
Mohamed Omran, Saker AM, El AdI MM, Abd \\ Elaziz MK, Youssif MKHM \\ Urology department, Zagazige University, Egypt
}

Correspondence: Mohamed Omran, Urology department, Zagazige University, Egypt, Email moh_omran2006@yahoo.com

Received: July 30, 2016 | Published: September 20, 2017

\section{Introduction}

Hypospadias is the most common penile congenital anomaly. ${ }^{2}$ and the second most common congenital malformation in males, occurring in approximately one in 125 live male births. ${ }^{3}$ Two theories were suggested for development of hypospadias, endodermal theory and ectodermal theory. ${ }^{4}$ Types of hypospadias are anterior, middle and posterior with the posterior type account approximately $20 \%$ of cases. Many surgical techniques were reported through history to correct this defect. ${ }^{3}$ Patients with severe proximal defects and those with failed previous repairs (crippled hypospadias) often require difficult reconstructive procedures with relatively high complication rates. ${ }^{4}$.Urethral reconstruction for primary and secondary hypospadias is best done using local penile and preputial tissues. ${ }^{5}$. Infrequently, local tissue is inadequate to provide both skin cover and reconstruction of the neourethra. This is usually encountered after previous surgical failure has led to tissue loss and scarring and only rarely in cases of untreated severe hypospadias. ${ }^{6}$ The use of buccal mucosa as urethral substitute material was first suggested by Humby in $1941,{ }^{7}$ and has been reintroduced by Burger, R A. and his groupsince in $1992 .{ }^{8}$ Various factors have contributed to the acknowledgement of buccal mucosal grafts (BMGs) as an ideal substitute for the urethra, including easy accessibility and manual handling, resistance to infection, compatibility with a wet environment, a thick epithelium and a thin lamina propria, allowing early inosculation and good medium-term results which are at least comparable with full-thickness skin grafts. ${ }^{9}$

\section{Materials and methods}

32 Patients included in this study divided in two groups. The $1^{\text {st }}$ group operated in one stage including 20 patients ( 8 primary, 6 crippled, 6 fistulae) and the $2^{\text {nd }}$ group operated in two stages including 12 patients (8 primary, 4 crippled) in the $1^{\text {st }}$ stage correction of associated genital anomalies done followed by urethroplasty 6 months later. 12 patients $(37.5 \%)$ had 14 genital anomalies 8 pts $(25 \%)$ had penile chordee ( 5 primary and 3 crippled), 2 pts ( 1 fistula and 1 in crippled) had penile rotation and 2 pts ( 1 primary and 1 crippled) had both chordee and penile rotation (Figure $1 \& 2$ ). Under general anesthesia with patient in supine position, two teams working simultaneously to decrease anesthesia time and leaving urethroplasty team to concentrate in his job. The harvesting of buccal mucosa from the lateral cheek was done with a technique similar to that described by Eppley et al. ${ }^{1}$ using an intraoral retractor and infiltrating the graft area with 1:200,000 epinephrine. The outlined graft is sharply dissected and removed, leaving the muscle intact. The donor site is carefully examined for bleeding. The graft length varied from 2.4 to $12.5 \mathrm{~cm}$, which was $20 \%$ more than the urethral plate defect length $(2-10.4 \mathrm{~cm})$ (Figure 3a \& 3b). The harvesting site is closed with 5-0 polyglactin continuous suture. Any fat or minor salivary glands harvested with the graft carefully removed to enhance graft survival.

For cases associated with chordee still present after degloving dorsal tunica albuginea plication at $12 \mathrm{o}$, clock as the Baskin \& Lue. ${ }^{10}$ modification of the technique described by Baskin \& Duckett. ${ }^{11}$ Buccal mucosal only urethroplasty then carried out starting by a few millimeters incision of the original meatus, to avoid post-operative urethral stricture that commonly occurs in this site, then the tip of the graft fixed to the meatus with 6-zero poliglecaprone sutures over a polyurethane catheter for both stenting and bladder drainage then completing the repair with continuous running sutures fixing the graft to both urethral plate wings till near the tip of the glans (Figure 4 \& 5). Second layer coverage of the neourethra was then secured over the 
urethra extending it to the deep groove under the glans wings. Tunica vaginalis flap used in 18 cases (11 in group one \& 7 in group two) or subcutaneous dartos flap which used in 14 cases (9 in groups one \& 5 in group two) as a second layer. Finally, skin coverage was done, by using the prepuce by Bayer flap technique, or by approximation of the penile skin in the ventral surface of the penis. Urethral stents extended to the bladder as a urethral catheter to compress it for 7 to 10 days (Figures $6 \& 7$ ).

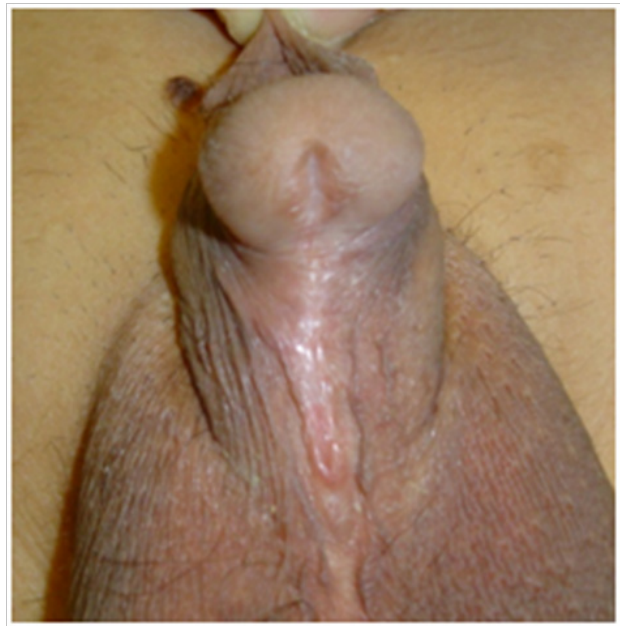

Figure I Peno-scrotal hypospadias chordee.

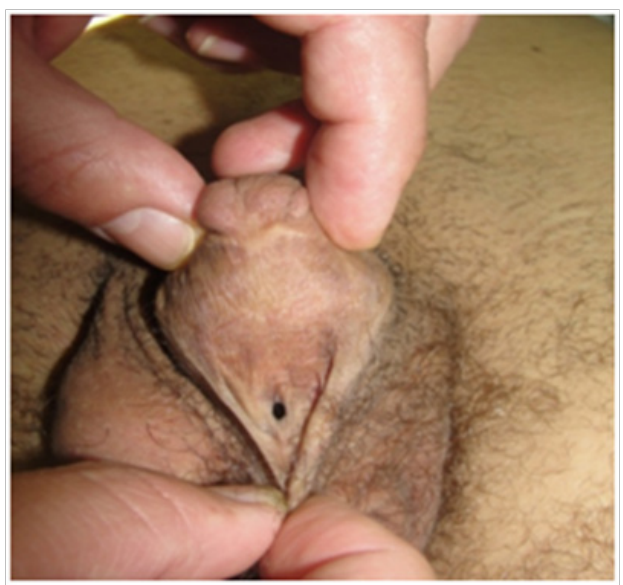

Figure 2 Crippled Peno-scrotal hypospadias with scared urethral plat \&deficient skin.

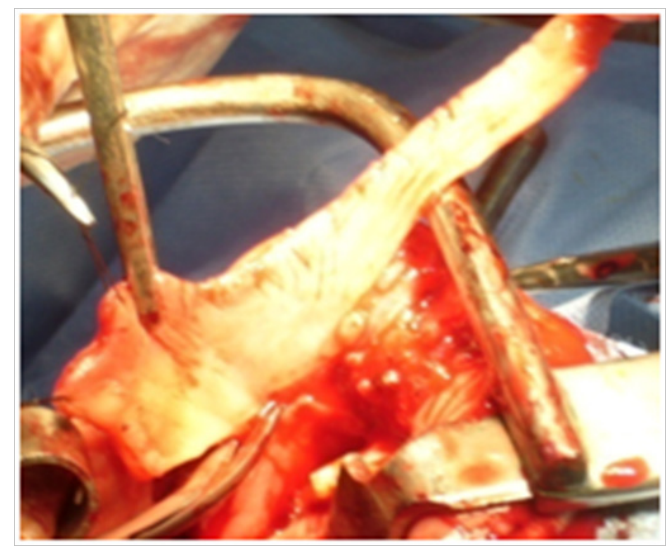

Figure 3A Harvesting the buccal mucosal graft.

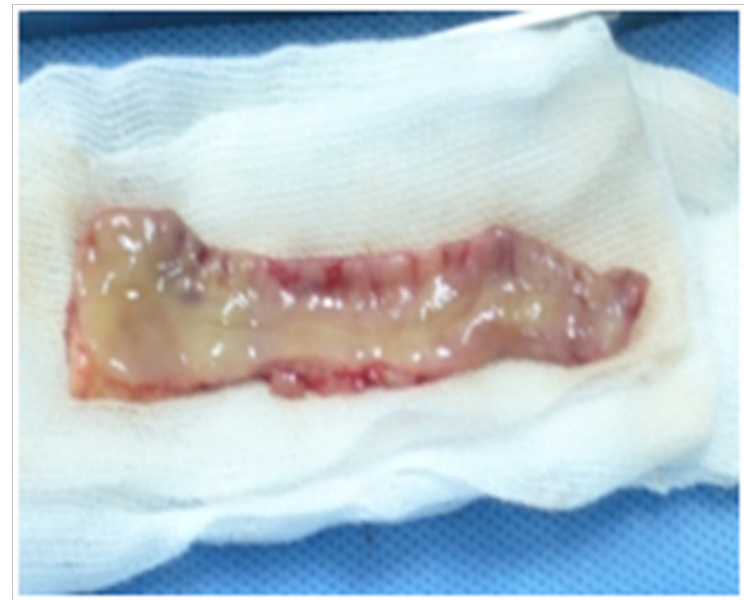

Figure 3B Buccal mucosa graft after harvesting.

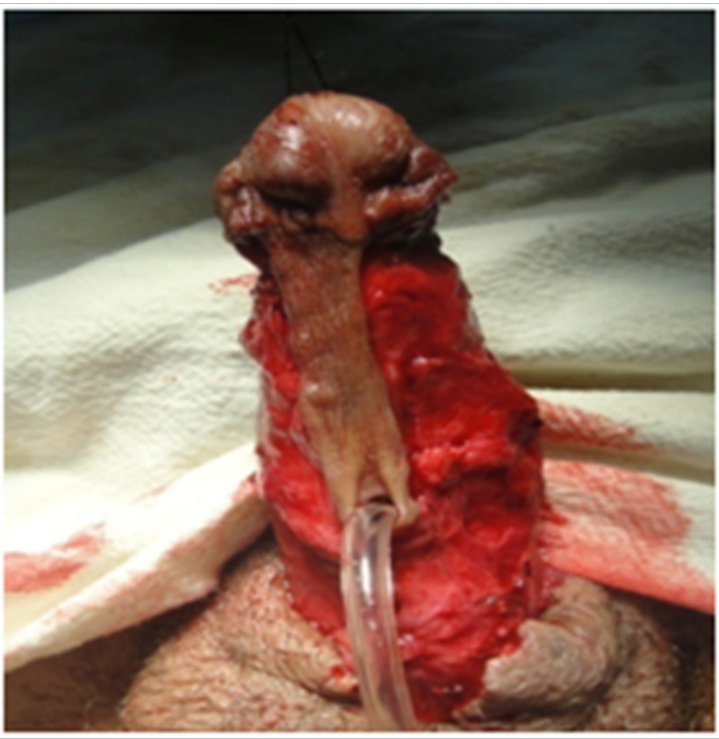

Figure 4 Penis with penoscrotal hypospadias after degloving.

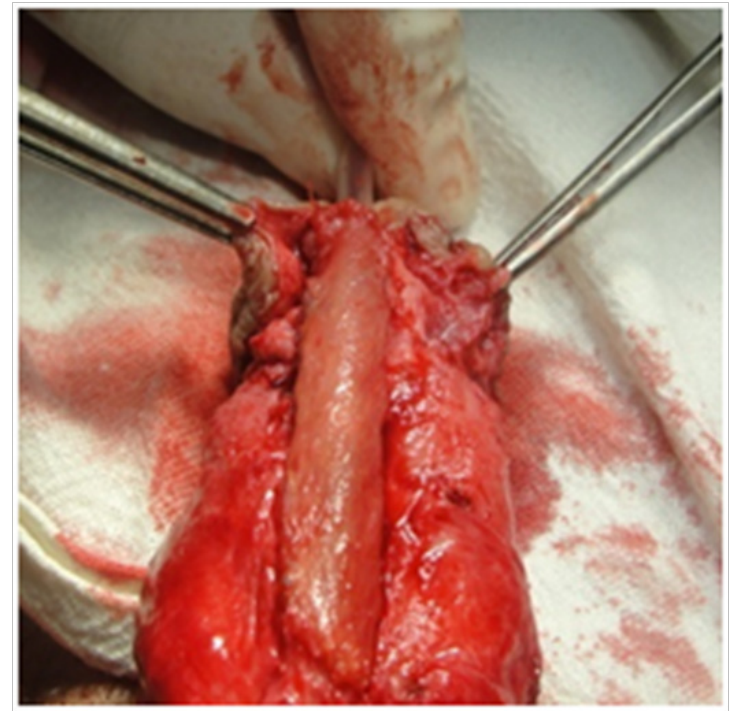

Figure 5 Ventral onlay buccal mucosa graft urethroplasty completed. 


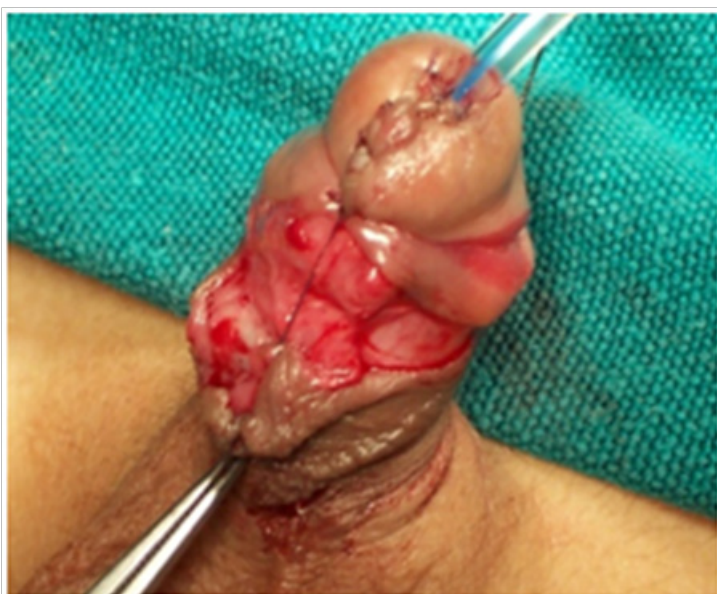

Figure 6 Glanuloplasty \& meatoplasty.

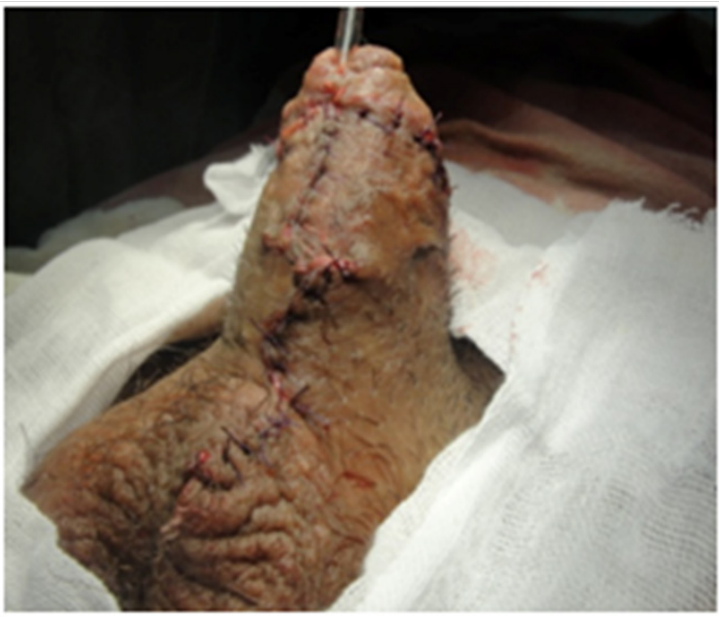

Figure 7 Final appearance in crippled case.

Fistula cases were associated with distal obstruction, incision made from the fistula to the tip of the glans creating hypospadias. Operative time ranged from 60 minutes to 110 minutes with mean of 81.5 minutes. In group one it ranged from $70-110$ (mean $84 \mathrm{~m}$ ), with time of graft harvesting ranged from 15 to 23 minutes. In group two in $2^{\mathrm{ND}}$ stage it ranged from 60to 100 minutes (mean 79) with time of graft harvesting ranged from 18 to 27 minutes. Follow up in group one ranged from 6 to 30 months with mean of 20 months while in group two it ranged from 6 to 24 months with mean of 17 months. Conservative management carried out for early complications as following. For edema NSAIDS used, for bleeding changing the dressing with compressive one in addition to anti bleeding drugs, for infection frequent changing the dressing with application of local antibiotic spray and for both glans and wound dehiscence frequent dressing and treatment of infection if present. For late complications conservative management was regular dilatation for both meatal stenosis and urethral stricture.

\section{Results}

Mean patient age was 6. years (range 8months to 23years). An early complication (Edema, Bleeding \& hematoma, Infection, Catheter problems, Glans dehiscence, Wound dehiscence, Fistulup two, 4 patients $(33.33 \%)$ complicated by 11 early complicata and graft loss) was 30 occurred in 10 patients (31.25\%). In group one, 18 complications occurred in 6 patients $(30 \%)$. In groions as shown in the Table 1. Among these 6 complicated cases in group one, 4 cases need reoperations for glans dehiscence and graft loss, wound dehiscence and fistula closure. But in group two among those 4 patients with early 11 complications only 2 patients need reoperation for glans dehiscence, wound dehiscence and fistula closure. The other cases respond to conservative management. Where late complications (meatal stenosis, urethral stricture, graft contracture and residual chordee) occurred as following, in group one 6 late complications occurred in 4 patients $(20 \%)$.

Table I Early complications

\begin{tabular}{ll}
\hline Complications & Number \\
\hline Edema & 7 \\
Bleeding \& Hematoma & 2 \\
Infection & 4 \\
Catheter problems & 3 \\
Glans Dehiscence & 4 \\
Wound Dehiscence & 3 \\
Graft Loss & 1 \\
Fistula & 5 \\
Total & 29
\end{tabular}

Where in group two 6 complications occurred in 3 patients $(25 \%)$ as shown in Table 2. In group one 3 patients need reoperations for meatal stenosis, urethral stricture and residual chordee $<30$, one of them reoperated also for early complications, so reoperation needed in group one for 3 early complications, 2 for late complications and 1 for both early and late complications and in group two only one patients need reoperations for meatal stenosis and urethral stricture as shown in Table 2. Reoperation procedures were fistula closure in 4 , meatoplasty in 3, VIU in 2 and arthroplasty in 2. From Table 3 the overall reoperation rate was $(28.125 \%), 6 / 20(30 \%)$ in group one and $3 / 12(25 \%)$ in group two.

Table 2 Late complications

\begin{tabular}{ll}
\hline Complications & Number \\
\hline Meatal stenosis & 5 \\
Urethral stricture & 4 \\
Residual chordee & 4 \\
Graft contracture & - \\
Total & 13 \\
\hline
\end{tabular}

Table 3 Reoperation rate

\begin{tabular}{lll}
\hline Number & Percent & \\
Primary & $4 / 16$ & $25 \%$ \\
\hline Crippled & $3 / 10$ & $30 \%$ \\
Fistulae & $2 / 6$ & $33.33 \%$ \\
Total & $9 / 32$ & $28.125 \%$ \\
\hline
\end{tabular}

\section{Discussion}

Urethral reconstruction for primary and secondary hypospadias is best done using local penile and preputial tissues. However, in a number of patients there is a paucity of local tissue to use for reconstruction, usually due to complications from previous hypospadias surgery. The use of buccal mucosa as urethral substitute material was first suggested by Humby in 1941, ${ }^{7}$ and has been reintroduced by Burger, R A. and his groupsince in 1992 Burger et al. ${ }^{8}$ In this study 32 patients underwent onlay buccal mucosal graft with second layer coverage 
of the neourethra with either tunica vaginalis flap or subcutaneous dartos flap. Follow up ranged from 6 to 30 months (mean 24 months). The results of this study shows that early complications occurred in 10 patients $(31.25 \%)$ and late complications occurred 6 patients (18, $75 \%$ ). The reoperation rate (which used as a failure rate) was $9 / 32$ $(28,125 \%)$. This reoperation rate is nearly the same as that reported by Yerkes et al. ${ }^{12}(29 \%)$. Higher than that of Fichtner et al. ${ }^{13}$ (24\%), that of Schoreder et al..$^{14}(22.4 \%)$, far away from that of Amukele et al. ${ }^{15}$ $(12 \%)$. But it is less than that of Metro et al. ${ }^{16}$ Nelson et al. ${ }^{4}$ and Irani et al. ${ }^{17}$ those reported $(50 \%),(51 \%)$ and $(50 \%)$ respectively.

The reoperation rate in group one (one stage repair) was 6/20 $(30 \%)$ less than that in the group two (two stages repair) which was $3 / 12(25 \%)$. which is more than that of Fichtner et al. ${ }^{13}$ in their 35 pts operated in one stage $(20 \%)$ and that for the 14 cases operated in two stages $(21 \%)$. Barbagli et al. ${ }^{18}$ reported the same success rate $(82 \%)$ in both one stage and two stages which are better than that in this study. Urethrocutaneous fistula occurred in 5 patients $(15,625 \%)$ with their distribution as following, 3 in group one (15\%) and 2 in group two $(16,67 \%), 2$ occurred with tunica vaginalis flap $2 / 18(11,11 \%)$ and 3 with subcutaneous dartos flap $3 / 14(21,4 \%)$ and 3 in 16 primary cases $(18,75 \%), 2$ in 10 crippled cases (20\%) and non in fistula cases. One fistula case in group one responds to conservative management with the other 4 cases need reoperations for closure $(12.5 \%)$.these fistula rates are nearly equal to that of Hensle et al. ${ }^{5}(14.3 \%)$ better than that of Yerkes et al. ${ }^{12}(29 \%)$ and Irani et al. ${ }^{17}(25 \%)$. where it is worse than that of Metro et al. ${ }^{16}(0 \%)$, Fichtner et al. ${ }^{13}(6.1 \%)$, Nelson et al. ${ }^{4}$ (11.6\%), Amukele et al. ${ }^{15}$ (3.6\%) and Schoreder et al. ${ }^{14}$ (3.5\%).

Meatal stenosis occurred in 5 cases, 3 in group one and 2 in group two, 3 in primary, 2 in crippled and non in fistula cases. One case in each group responds to meatal dilatation leaving only 3 cases $(9.375 \%)$ for meatoplasty. This rate is near to that of Schoreder et al. ${ }^{14}(8.2 \%)$, better than that of Metro et al. ${ }^{16}$ (14.3\%) And Nelson et al. ${ }^{4}(11.6 \%)$ but it is worse than that of Fichtner et al. ${ }^{13}(4.08 \%)$ and that of Yerkes et al. ${ }^{12}$, Hensle et al.. ${ }^{5}$, Amukele et al. ${ }^{15}$ and Irani et al.. ${ }^{17}$ all reported $0 \%$ meatal stenosis. Stricture urethra occurred in 3 cases $(9,375 \%), 1$ in group one (5\%) and 2 in group two $(16.67 \%)$, the all 3 cases were primary cases. One case respond to regular dilatation leaving 2 cases $(6.25 \%)$ which respond will for VIU with no case need urethroplasty. These rates is better than that of Metro et al. ${ }^{16}(42.8 \%)$ and that of Nelson et al. ${ }^{4}(14 \%)$, near to that of Fichtner et al. ${ }^{13}(6.1 \%)$, worse than that of Amukele et al. ${ }^{15}$ (3.6\%), Schoreder et al..$^{14}(3.5 \%)$ and that of Yerkes et al. ${ }^{12}$, Hensle et al. ${ }^{5}$ and Irani et al. ${ }^{17}$ which reported $(0 \%)$ stricture urethra.

Residual chordee occurred in 4 cases $(12,5 \%), 2$ in group one $(10 \%)$ and 2 in group two $(16,67 \%)$. The two cases in group one need orthoplasty as the residual chordee was $<30$ while the two cases in group two the residual chordee was $>30$ so no intervention done. Graft loss occurred only in one fistula case that complicated by complete wound dehiscence. This is near to that of Hensle et al. ${ }^{5}$ $(5.7 \%)$. No graft contracture occurred as we harvested the graft with a $20 \%$ more length than the urethral defect to overcome that problem that can occurs. ${ }^{19,20}$

\section{Conclusion}

Buccal mucosa apecrease fistula formation and to add a new vascularity helping imbibition and inosculatpears to be a durable source of non-genital tissue for urethral replacement. Only buccal mucosa arthroplasty for complex hypospadias repair is of good results obtained with one stage or two stages repair with better results in two stage approach. Also good results obtained in primary, crippled and fistulae cases with better results in primary cases. The addition of a second layer coverage to the newly formed urethra either tunica vaginalis flap or subcutaneous dartos flap is important to Dion of the only buccal mucosa graft.

\section{Acknowledgements}

None.

\section{Conflicts of interest}

All authors declared there are no conflicts of interest.

\section{Funding}

None.

\section{References}

1. Eppley BL, Keating M, Rink R.A buccal mucosal harvesting technique for urethral reconstruction. J Urol. 1997;157(4):1268-1270.

2. Fredell L, Kockum I, Hansson E, et al. Heredity of hypospadias and the significance of low birth weight. J Urol. 2002;167(3):1423-1427.

3. Manson JM, Carr MC. Molecular epidemiology of hypospadias:review of genetic and environmental risk factors. Birth Defects Res A Clin Mol Teratol. 2003;67(10):825-836.

4. Nelson CP, Bloom DA, Kinast R, et al. Long term reported outcome and satisfaction after oral mucosa graft urethroplasty for hypospadias. $J$ Urol. 2005;174(3):1075-1078.

5. Hensle TW, Kearney MC, Bingham JB. Buccal mucosa grafts for hypospadias surgery:long-term results. J Urol. 2002;168(4 Pt 2):1734 1737.

6. Ahmed S, Gough DC. Buccal mucosal graft for secondary hypospadias repair and urethral replacement. Br J Urol. 1997;80(2):328-330.

7. Humby GA, Higgins TT. A one-stage operation for hypospadias. Br J Surg. 1941;29(113):84-92.

8. Bürger RA, Müller SC, el-Damanhoury H, et al. The buccal mucosal graft for urethral reconstruction:a preliminary report. $J$ Urol. 1992;147(3):662-664.

9. Bharagava S, Chapple CR. Department of Urology, Section of Reconstruction, Urodynamics and Female Urology. UK: Royal Hallamshire Hospital; 2003.

10. Baskin LS, Lue TF. The correction of congenital penile curvature in young men. Br J Urol. 1998;81(6):895-899.

11. Baskin LS, Duckett JW. Dorsal tunica albuginea plication for hypospadias curvature. J Urol1994;. 1994;151(6):1668-1671.

12. Yerkes EB, Adams MC, Miller DA, et al. Coronal cuff:a problem site for buccal mucosal grafts. J Urol. 1999;162(4):1442-1444.

13. Fichtner J, Filipas D, Fisch M, et al. Long-term follow up of buccal mucosa onlay graft for hypospadias repair: analysis of complications. $J$ Urol . 2004;72(5 Pt 1):1970-1972.

14. Schroeder A, Stein R, Fiedler M, et al. Long-term results of buccal mucosa onlay grafts in hypospadias repair. ESPU Programme. 2004;6(1):S80.

15. Amukele SA, Stock JA, Hanna MK. Management and outcome of complex hypospadias repairs. 2005;174(4):1540-1543.

16. Metro MJ, Wu HY, Snyder HM, et al. Buccal mucosal grafts: lessons learned from an 8-year experience. J Urol. 2001;166(4):1459-1461.

17. Irani D, Hekmati P, Sharifi AA. Results of buccal mucosal graft urethroplasty in complex hypospadias. Urology J. 2005;2(2):111-114. 
18. Barbagli G, De Angelis M, Palminteri E, et al. Failed hypospadias repair presenting in adults. Eur Urol. 2006;49(5):887-895.

19. Glenn JF, Anderson EE. Surgical correction of incomplete penoscrotal transposition. J Urol. 1973;110(5):603-605.
20. Thiersch C. Ueber die entstehungsweise und operative behandlung der epispadie. Arch Heilkund. 1869;10:20-35. 